\title{
Aestuariimicrobium ganziense sp. nov., a new Gram-positive bacterium isolated from soil in the Ganzi Tibetan Autonomous Prefecture, China
}

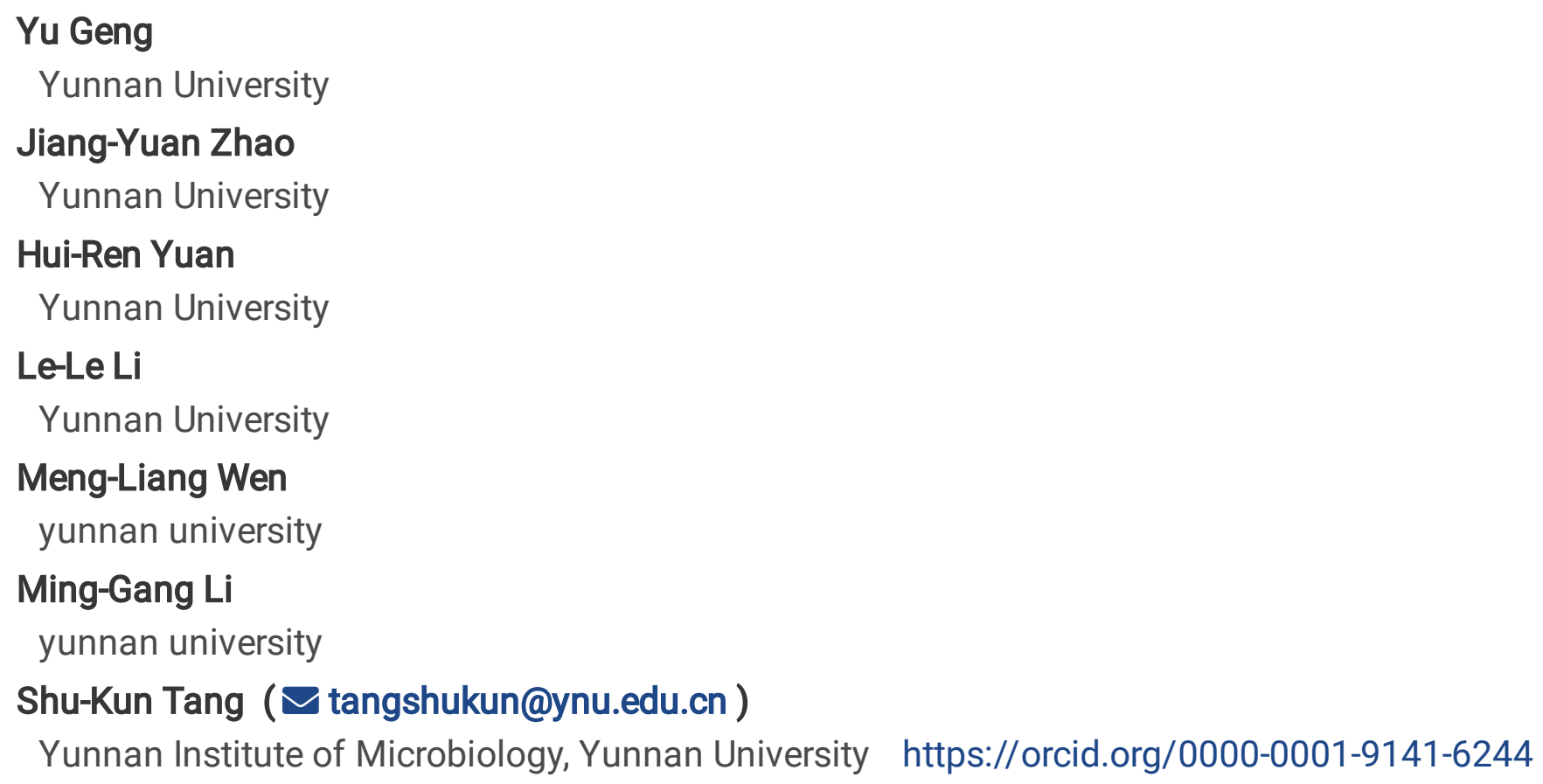

\section{Research Article}

Keywords: Aestuariimicrobium ganziense sp. nov., Chemotaxonomy, 16S rRNA sequence analysis

Posted Date: February 11th, 2021

DOl: https://doi.org/10.21203/rs.3.rs-215613/v1

License: (9) This work is licensed under a Creative Commons Attribution 4.0 International License. Read Full License

Version of Record: A version of this preprint was published at Archives of Microbiology on March 12th, 2021. See the published version at https://doi.org/10.1007/s00203-021-02261-2. 


\section{Abstract}

A novel Gram-stain positive, oval shaped and non-flagellated bacterium, designated YIM S02566 ${ }^{\top}$, was isolated from alpine soil in Shadui Towns, Ganzi County, Ganzi Tibetan Autonomous Prefecture, Sichuan Province, PR China. Growth occurred at $23-35^{\circ} \mathrm{C}$ (optimum, $30^{\circ} \mathrm{C}$ ) in the presence of $0.5-4 \%(\mathrm{w} / \mathrm{v}) \mathrm{NaCl}$ (optimum, 1\%) and at pH 7.0-8.0 (optimum, pH 7.0). The phylogenetic analysis based on 16S rRNA gene sequence revealed that strain YIM S02566 ${ }^{\top}$ was most closely related to the genus Aestuariimicrobium, with Aestuariimicrobium kwangyangense $\mathrm{R}^{2} 7^{\top}$ and Aestuariimicrobium soli $\mathrm{D}^{\top}$ as its closest relative (sequence similarities were $96.3 \%$ and $95.4 \%$, respectively). YIM S02566 ${ }^{\top}$ contained LL-diaminopimelic acid in the cell wall. MK-9(H4) was the predominant menaquinone. The major fatty acid patterns were anteiso- $\mathrm{C}_{15: 0}(60.0 \%)$. The major polar lipid was DPG. The genome size of strain YIM S02566 ${ }^{\top}$ was 3.1 $\mathrm{Mb}$, comprising 3078 predicted genes with a DNA G + C content of $69.0 \mathrm{~mol} \%$. Based on these genotypic, chemotaxonomic and phenotypic evidences, strain YIM S02566 ${ }^{\top}$ was identified as a novel species in the genus Aestuariimicrobium, for which the name Aestuariimicrobium ganziense sp. nov. is proposed. The type strain is YIM S02566 ${ }^{\top}$ (= CGMCC $1.18751^{\top}=$ KCTC $\left.49477^{\top}\right)$.

\section{Introduction}

The genus Aestuariimicrobium, first described by Jung et al. (2007), is a member of the family Propionibacteriaceae within the order Propionibacteriales, class Actinomycetia (Stackebrandt 2014; Stackebrandt et al. 1997; Stackebrandt et al. 2002a). Up to now, this genus comprises only two recognized species (http://www. bacterio. net/), Aestuariimicrobium kwangyangense (found in tidal flat sediment) and Aestuariimicrobium soli (found in farmland soil). In this study, a yellow bacterial strain YIM S02566 ${ }^{\top}$ was isolated from alpine soil in Shadui Towns, Ganzi County, Ganzi Tibetan Autonomous Prefecture, Sichuan Province, PR China, and was identified as the third strain of the genus Aestuariimicrobium (Chen et al. 2018) by means of a polyphasic taxonomic study. On the basis of the data obtained, we propose that isolate YIM S02566 ${ }^{\top}$ represents a novel species in the genus Aestuariimicrobium.

\section{Methods And Materials}

\section{Bacterial isolation and cultivation}

Strain YIM S02566 ${ }^{\top}$ was isolated from a soil sample in the Shadui Towns, Ganzi County, Ganzi Tibetan Autonomous Prefecture, Sichuan Province, PR China $\left(31^{\circ} 49^{\prime} 24.19^{\prime \prime} \mathrm{N}, 100^{\circ} 15^{\prime} 28.90 " \mathrm{E}\right)$. The altitude of the sample collection was $4643.88 \mathrm{~m} .2 \mathrm{~g}$ of soil sample was serially diluted $\left(10^{-1}\right.$ dilution), and approximately $100 \mu \mathrm{l}$ of the diluted culture suspension was spread on Luria-Bertani (LB) agar. The plates were then incubated at $30^{\circ} \mathrm{C}$ for 10 days. Strain YIM S02566 ${ }^{\top}$ was one of the isolates that appeared on the LB plates under aerobic condition. Single colonies were purified by transferring them onto R2A 
(Reasoner's 2A) agar plates with $1 \% \mathrm{NaCl}$. It was stored on R2A at $4{ }^{\circ} \mathrm{C}$ and as a glycerol suspension $(20 \%, v / v)$ at $-80^{\circ} \mathrm{C}$.

\section{Phenotypic, physiological and biochemical characteristics}

Cell morphology characteristics of strain YIM S02566 ${ }^{\top}$ was assessed by transmission electron microscopy (JEM-2100, JEOL) after 5 days of incubation on R2A with $1 \% \mathrm{NaCl}$ at $30^{\circ} \mathrm{C}$. The Gram reaction was performed using the commercial kit, following the instruction of the manufacturer (Solarbio). The temperature range of growth $\left(4,10,15,18,20,23,25,28,30,33,35,37,40\right.$ and $45^{\circ} \mathrm{C}$ ) and $\mathrm{NaCl}$ tolerance concentrations $(0,0.5,1,2,3$ and $4-12 \%$ at intervals of $2 \%, w / v)$ were measured by using R2A medium at $30^{\circ} \mathrm{C}$ for 10 days. The $\mathrm{pH}$ tolerance $(6,7,7.5,8,9,10)$ for growth were determined on R2A liquid medium for 10 days at $30^{\circ} \mathrm{C}$ using the buffer system described by Tang et al. (2010). Catalase activity was determined by production of bubbles after adding $3 \% \mathrm{H}_{2} \mathrm{O}_{2}$ to the tested bacteria (Tarrand and Groschel 1982). Tests for hydrolysis of Tween 20, 40, 60 and 80 were determined by using traditional methods (Yang et al. 2020). Carbon source utilization tests, enzyme activity tests, acid production and additional physiological and biochemical tests were performed using Biolog GEN III microplates (Biolog), API ZYM, API $50 \mathrm{CH}$ and API 20NE kits (bioMérieux) according to the manufacturer's instructions. Susceptibility to antibiotics was tested on R2A agar with $1 \% \mathrm{NaCl}$ plates using discs containing the following concentrations of antibiotic (per disc): erythromycin $(15 \mu \mathrm{g})$, cefoperazone (30 $\mu \mathrm{g})$, tetracycline $(30 \mu \mathrm{g})$, kanamycin $(30 \mu \mathrm{g})$, ciprofloxacin $(5 \mu \mathrm{g})$, furazolidone $(300 \mu \mathrm{g})$, cefazolin $(30 \mu \mathrm{g})$, rifampin $(5 \mu \mathrm{g})$, polymyxin $B(300 \mathrm{U})$, ampicillin $(10 \mu \mathrm{g})$, penicillin $(10 \mathrm{U})$, gentamicin $(10 \mathrm{ug})$, chloramphenicol $(30 \mathrm{ug})$, streptomycin (10 ug), bacitracin (0.04 U), cefoperazone (75 ug), clindamycin (2 ug), minomycin (30 ug), norfloxacin (10 ug), ofloxacin (5 ug), piperacillin (100 ug).

\section{Phylogenetic analyses and genome sequencing}

Genomic DNA for Polymerase Chain Reaction (PCR) amplification was extracted using the method described by Feng et al. (2020). The 16S rRNA gene was amplified by PCR with the universal primers PA (5'-CAG AGT TTG ATC CTG GCT-3') and PB (5'-AGG AGG TGA TCCAGC CGC A-3') (Yang et al. 2020). The amplicon was cloned into PEASY-Blunt (TRANSGEN Biotech) and then sequenced by the Tsingke Company (Beijing, PR China). Comparison of 16S rRNA with related strains was conducted by EzTaxon server (https ://www.ezbiocloud.net/) (Yoon et al. 2017). A total of 15 species form 13 genera were used in this study. Terrabacter tumescens was selected as the outgroup. All sequences used for phylogenetic analysis were obtained from GenBank, and accession numbers were listed in Fig.1. Multiple alignments with corresponding sequences of the most closely relatives were executed using the CLUSTAL X 1.8 program (Thompson et al. 1997). Phylogenetic analyses were performed by MEGA version 7.0 software (Kumar et al. 2016) using neighbor-joining (NJ) (Saitou and Nei 1987), Maximum Parsimony (MP) (Fitch 1971) and Maximum-Likelihood (ML) (Felsenstein 1981) methods, with bootstrap values based on 1000 replications (Felsenstein 1985). 
The genome sequences of YIM S02566 ${ }^{\top}$ were determined using a PacBio + Illumina Hiseq at Shanghai Majorbio Bio-pharm Technology Co., Ltd (Shanghai, China). The sequenced reads were assembled using SOAPdenovo software version 2.04 (https://soap.genom ics.org.cn/soap.enovo.html). The DNA G+C mol\% value was obtained from the genomic sequences. A genome tree was constructed using RAxML (Stamatakis 2014), and fast bootstrapping (Stamatakis et al. 2008) was used to generate the support values in the tree.

\section{Chemotaxonomic characteristics}

The strain biomass for chemotaxonomic characterization was obtained from 5-days old cultures grown on medium R2A with $1 \% \mathrm{NaCl}$ at $30^{\circ} \mathrm{C}$. The isomer type of the diaminopimelic acid of the cell wall was analyzed according to the method described by Lechevalier (Lechevalier and Lechevalier 1971). The respiratory quinones were isolated using the method of Collins et al. (1977), and analyzed by HPLC (Agilent Technologies 1260 Infinity) (Groth et al. 1996). Polar lipids profiles were analyzed as described by two-dimensional TLC (Minnikin et al. 1984; Toru et al. 1983), and the different spots were observed by spraying with the proper detection reagents (molybdophosphoric acid, molybdenum blue, ninhydrin, $\mathrm{D}$ reagent and a-naphthol). The cellular fatty acids were extracted and analyzed according to the standard MIDI Protocol (Microbial Identification) and Sherlock Microbial Identification System (Sherlock version 6.1; midi database: TSBA6).

\section{Results And Discussion}

\section{Morphological and physiological characteristics}

The colonies of the strain YIM S02566 ${ }^{\top}$ was Gram positive, oval-shaped, non-flagellated, yellow and 0.5$1.0 \mu \mathrm{m}$ in diameter after 5 days of incubation at $30^{\circ} \mathrm{C}$ (Fig. S1). Other phenotypic and physiological characteristics of YIM S02566 ${ }^{\top}$ and its related members are given in Table 1, Table S1 and in the species description.

\section{Phylogenetic analysis}

The almost complete 16S rRNA gene sequence (1509 bp) of strain YIM S02566 ${ }^{\top}$ was generated, and displayed $96.3 \%$ 16S rRNA gene sequence identity with Aestuariimicrobium kwangyangense R27' ${ }^{\top}$. The next highly related species was Aestuariimicrobium soli $\mathrm{D6}^{\top}$, with pairwise similarities of $95.4 \%$. The NJ tree, MP tree and ML tree for the 16S rRNA shared the same topology and were presented in Fig. 1, Fig. S2 and Fig. S3, respectively. The phylogenetic tree indicated that strain YIM S02566 ${ }^{\top}$ clustered with Aestuariimicrobium kwangyangense $\mathrm{R} 27^{\top}$ and Aestuariimicrobium soli $\mathrm{D}^{\top}{ }^{\top}$.

The draft genome sequence of strain YIM S02566 ${ }^{\top}$ consisted of 68 scaffolds with the N50 value of 449246, and contained 3078 coding sequences (CDSs), 3 complete rRNA genes, 44 tRNA genes. A phylogenetic tree based on genome sequences was reconstructed using RaxML to confirm the 
relationships already displayed in the $16 \mathrm{~S}$ rRNA gene based tree, with YIM S02566 ${ }^{\top}$ as a part of the genus Aestuariimicrobium(Fig. S4).

\section{Chemotaxonomic characteristics}

Strain YIM S02566 ${ }^{\top}$ contained LL-diaminopimelic acid as the diagnostic cell wall diamino acid. The predominant isoprenoid quinone was $\left[\mathrm{MK}-9\left(\mathrm{H}_{4}\right)\right]$, which was the same as the members of the family Propionibacteriaceae (Bae et al. 2006; Chen et al. 2018; Collins et al. 2003; Jung et al. 2007; Nakamura et al. 1995; Stackebrandt et al. 2002a; Tamura et al. 1994; Yokota et al. 1994). The major polar lipid was diphosphatidylglycerol (DPG) (Fig. S5). The major fatty acids (>10\%) of strain YIM S02566 ${ }^{\top}$ was anteiso$\mathrm{C}_{15: 0}(60.0 \%)$. Compared with the data of other two reference strains, anteiso- $\mathrm{C}_{15: 0}$ was the major fatty acid of all strains (Table 2).

The combination of phenotypic (Table 1), phylogenetic (Fig. 1 and Fig. S4), and chemotaxonomic characteristics indicates that strain YIM S02566 ${ }^{\top}$ represents a novel species within the genus Aestuariimicrobium, for which the name Aestuariimicrobium ganziense is proposed.

\section{Description of Aestuariimicrobium ganziense sp. nov.}

Aestuariimicrobium ganziense (gan.zi.en'se. N.L. masc. adj. ganziense pertaining to Ganzi, China, from where the type strain was isolated).

Gram-stain positive, non-flagellated, oval shaped (approximately $0.5 \times 0.7 \mu \mathrm{m}$ ) bacterium, and growth occurred at $23-35^{\circ} \mathrm{C}$ (optimum, $30^{\circ} \mathrm{C}$ ) in the presence of $0.5-4 \%(\mathrm{w} / \mathrm{v}) \mathrm{NaCl}$ (optimum, $1 \%$ ) and at pH 7.08.0 (optimum, $\mathrm{pH} 7.0$ ). The gram staining reaction, catalase activity, hydrolysis of Tween $20,40,60$ and 80 tests are positive. In API 20NE tests, positive for nitrate reduction, aesculin hydrolysis, protease hydrolysis, $\beta$-galactosidase activity, assimilation of L- arabinose, D-mannose, capric acid. In API ZYM tests, positive for esterase (C4), esterase lipase (C8), leucine arylamidase, valine arylamidase, trypsin, acid phosphomonoesterase, naphthol-AS-B/-phosphoric acid, $\alpha$-galactosidase, $\beta$-galactosidase, $\alpha$ glucosidase, $\beta$-glucosidase, $N$-acetyl- $\beta$-glucosaminase, $\alpha$-mannosidase, and $\beta$-fucosidase. In API $50 \mathrm{CH}$ tests, acid is produced from L-arabinose, D-xylose, L-xylose, D-galactose, D-glucose, fructose, D-mannose, L- sorbose, L-rhamnose, methyl-ad-glucopyranoside, amygdalin, arbulin, aesculin, salicin, D-cellobiose, Dmaltose, D-lactose, D-melibiose, D-saccharose, D-trehalose, D-melezitose, D-raffinose, amidon (starch), glycogen, xylitol, D-gentiobiose, D-turanose, D-lyxose, L-fucose. In the Biolog GEN III MicroPlate system, grows in the presence of dextrin, D-trehalose, gentiobiose, sucrose, stachyose, D-raffinose, $\beta$-methyl-Dglucoside, D-salicin, D-galactose, D-fucose, L-fucose, D-sorbitol, D-arabitol, myo-inositol, D-serine, gelatin, L-alanine, L-pyroglutamic acid, pectin, D-galacturonic acid, D-glucuronic acid, glucuronamide, $a$-ketoglutaric acid, tween 40 , acetoacetic acid, propionic acid, acetic acid, formic acid. The strain is susceptible to penicillin $(10 \mathrm{IU})$, chloramphenicol $(30 \mu \mathrm{g})$, tetracycline $(30 \mu \mathrm{g})$, ceftriaxone $(30 \mu \mathrm{g})$, cefazolin $(30 \mu \mathrm{g})$, ciprofloxacin $(5 \mu \mathrm{g})$, ofloxacin $(5 \mu \mathrm{g})$, erythromycin $(15 \mu \mathrm{g})$, rifampin $(5 \mu \mathrm{g})$, gentamicin $(10 \mu \mathrm{g})$, minocycline $(30 \mu \mathrm{g})$, but not toclindamycin $(2 \mu \mathrm{g})$, kanamycin $(30 \mu \mathrm{g})$, polymyxin B (300 IU), piperacillin 
$(100 \mu \mathrm{g})$, cefoperazone $(75 \mu \mathrm{g})$, ampicillin $(10 \mu \mathrm{g})$, bacitracin $(0.04 \mathrm{IU})$, streptomycin $(10 \mu \mathrm{g})$, norfloxacin $(10 \mu \mathrm{g})$,furazolidone $(300 \mu \mathrm{g})$. The major polar lipid is diphosphatidylglycerol (DPG). The predominant menaquinone is MK-9 $\left(\mathrm{H}_{4}\right)$. The cell wall contains LL-diaminopimelic acid. The fatty acids are anteiso$\mathrm{C}_{15: 0}(60.0 \%)$. The DNA G + C content of the type strain is $69.0 \mathrm{~mol} \%$.

The type strain YIM S02566 $\left(=C G M C C 1.18751^{\top}=\right.$ KCTC $\left.49477^{\top}\right)$ was isolated from a soil sample in the Shadui Towns, Ganzi County, Ganzi Tibetan Autonomous Prefecture, Sichuan Province, PR China $\left(31^{\circ} 49^{\prime} 24.19^{\prime \prime} \mathrm{N}, 100^{\circ} 15^{\prime} 28.90^{\prime \prime} \mathrm{E}\right)$, the altitude of the sample collection is $4643.88 \mathrm{~m}$. The GenBank accession numbers of the $16 \mathrm{~S}$ rRNA gene and the genome sequence of YIM S02566 ${ }^{\top}$ are MW023203 and JACYIZ000000000, respectively.

\section{Declarations}

\section{Acknowledgements}

We thank Zhenyu Lv from the Kunming Institute of Botany, Chinese Academy of Sciences for the help in sample collection.

\section{Funding}

This work was supported by Major Science and Technology Projects of Yunnan Province (Digitalization, development and application of biotic resource 202002AA100007), National Natural Science Foundation of China (31760019) and Basic Research Project of Yunnan Province (202001BB050025).

\section{Conflicts of interest}

The authors declare that there are no conflicts of interest.

\section{References}

Bae HS, Moe WM, Yan J, Tiago I, Da Costa MS, Rainey FA (2006) Brooklawnia cerclae gen. nov., sp. nov., a propionate-forming bacterium isolated from chlorosolvent-contaminated groundwater. Int J Syst Evol Microbiol 56:1977-1983

Chen LL, Chen F, Zhao HZ, Feng ZZ, Zhang H, Huang X (2018) Aestuariimicrobium soli sp. nov., isolated from farmland soil, and emended description of the genus Aestuariimicrobium. Int J Syst Evol Microbiol 68:3296-3300

Collins MD, Hutson RA, Nikolaitchouk N, Nyberg A, Falsen E (2003) Luteococcus sanguinis sp. nov., isolated from human blood. Int J Syst Evol Microbiol 53:1889-1891

Collins MD, Pirouz T, Goodfellow M, Minnikin DE (1977) Distribution of menaquinones in Actinomycetes and Corynebacteria. J Gen Microbiol 100:221-230 
Felsenstein J (1981) Evolutionary Trees from DNA-Sequences-a Maximum-Likelihood Approach. J Mol Evol 17:368-376

Felsenstein J (1985) Confidence limits on Phylogenies: an approach using the bootstrap. Evolution 39:783-791

Feng YZ, Chunyu WX, Liang R, Hahnke RL, Schumann P (2020). Vallicoccus soli gen. nov., sp. nov., a novel actinobacterium isolated from soil, and description of Vallicoccaceae fam. nov., Motilibacterales ord. nov. Antonie Van Leeuwenhoek 12:2155-2165

Fitch WM (1971) Toward defining the course of evolution: minimum change for a specific tree topology. Syst Zool 20:406-416

Groth I, Schumann P, Weiss N, Martin K, Rainey FA (1996) Agrococcus jenensis gen. nov., sp. nov., a new genus of actinomycetes with diaminobutyric acid in the cell wall. Int J Syst Bacteriol 46:234-239

Jung SY, Kim HS, Song JJ, Lee SG, Oh TK, Yoon JH (2007) Aestuariimicrobium kwangyangense gen. nov., sp. nov., an LL-diaminopimelic acid-containing bacterium isolated from tidal flat sediment. Int J Syst Evol Microbiol 57:2114-2118

Kumar S, Stecher G, Tamura K (2016) MEGA7: Molecular Evolutionary Genetics Analysis Version 7.0 for Bigger Datasets. Mol Biol Evol 33:1870-1874

Lechevalier MP, Lechevalier HJAiAM (1971) Chemical composition as a criterion in the classification of aerobic actinomycetes. Advances in Applied Microbiology 14:47-72

Minnikin DE, O'Donnell AG, Goodfellow M, Alderson G, Athalye M, Schaal A, Parlett JHJJoMM (1984) An integrated procedure for the extraction of bacterial isoprenoid quinones and polar lipids. $J$ Microbiol Methods 2:233-241

Nakamura K, Hiraishi A, Yoshimi Y, Kawaharasaki M, Masuda K, Kamagata Y (1995) Microlunatus phosphovorus gen. nov., sp. nov., a new gram-positive polyphosphate-accumulating bacterium isolated from activated sludge. Int J Syst Bacteriol 45:17-22

Saitou N, Nei M (1987) The neighbor-joining method: a new method for reconstructing phylogenetic trees. Mol Biol Evol 4:406-425

Stackebrandt E (2014) The Family Propionibacteriaceae: Genera other than Propionibacterium. Springer Berlin Heidelberg, prokaryotes 725-741

Stackebrandt E, Rainey FA, WardRainey NL (1997) Proposal for a new hierarchic classification system, Actinobacteria classis nov. Int J Syst Bacteriol 47:479-491 
Stackebrandt E, Schumann P, Schaal KP, Weiss N (2002a) Propionimicrobium gen. nov., a new genus to accommodate Propionibacterium lymphophilum (Torrey 1916) Johnson and Cummins 1972, 1057AL as Propionimicrobium lymphophilum comb. nov. Int J Syst Evol Microbiol 52:1925-1927

Stamatakis A. RAxML version 8: a tool for phylogenetic analysis and post- analysis of large phylogenies. Bioinformatics 30:1312-1313.

Stamatakis A, Hoover P, Rougemont J. A rapid bootstrap algorithm for the RAxML web servers. Syst Biol 57:758-771.

Tamura T, Takeuchi M, Yokota A (1994) Luteococcus japonicus gen. nov., sp. nov., a new gram-positive coccus with LL-diaminopimelic acid in the cell wall. Int J Syst Bacteriol 44:348-356

Tang SK, Wang Y, Chen Y, Lou K, Cao LL, Xu LH, Li WJ (2009) Zhihengliuella alba sp. nov., and emended description of the genus Zhihengliuella. Int J Syst Evol Microbiol 59:2025-2031

Tang SK, Wang Y, Zhang H, Lee JC, Lou K, Kim CJ, Li WJ (2010) Haloechinothrix alba gen. nov., sp. nov., a halophilic, filamentous actinomycete of the suborder Pseudonocardineae. Int J Syst Evol Microbiol 60:2154-2158

Tarrand JJ, Gröschel DH (1982) Rapid, modified oxidase test for oxidase-variable bacterial isolates. J Clin Microbiol 16:772-774

Thompson JD, Gibson TJ, Plewniak F, Jeanmougin F, Higgins DG (1997) The CLUSTAL_X windows interface: flexible strategies for multiple sequence alignment aided by quality analysis tools. Nucleic Acids Res 25:4876-4882

Toru, Hasegawa, Masayuki, Takizawa, Seiichi, General TJJo, Microbiology A (1983) A rapid analysis for chemical grouping of aerobic actinomycetes. J Gen Microbiol 29:319-322

Yang L, Huang HW, Wang Y, Kou YR, Tang SK(2020) Paenibacillus turpanensis sp. nov., isolated from a salt lake of Turpan city in Xinjiang province, north-west China. Arch Microbiol 2020:1-7

Yokota A, Tamura T, Takeuchi M, Weiss N, Stackebrandt EJIJSB (1994) Transfer of Propionibacterium innocuum Pitcher and Collins 1991 to Propioniferax gen. nov. as Propioniferax innocua comb. nov. Int J Syst Evol Microbiol 44:579-582

Yoon SH, Ha SM, Kwon S, Lim J, Kim Y, Seo H, Chun J (2017) Introducing EzBioCloud: a taxonomically united database of 16S rRNA gene sequences and whole-genome assemblies. Int J Syst Evol Microbiol 67:1613-1617

\section{Tables}

Table 1 Comparative characteristics of strain YIM S02566 ${ }^{\top}$ and type strains of closely related species 


\begin{tabular}{|c|c|c|c|}
\hline Characteristic & YIM S02566 ${ }^{\top}$ & A. kwangyangense $\mathrm{R} 27^{\top}$ & A. soli D6 ${ }^{\top}$ \\
\hline Colony color & Yellow & Yellow & Yellow \\
\hline \multicolumn{4}{|l|}{ Growth temperature } \\
\hline Range & $23-35^{\circ} \mathrm{C}$ & $4-50^{\circ} \mathrm{C}$ & $4-37^{\circ} \mathrm{C}$ \\
\hline Optimum & $30^{\circ} \mathrm{C}$ & $30^{\circ} \mathrm{C}$ & $30^{\circ} \mathrm{C}$ \\
\hline \multicolumn{4}{|l|}{ Growth pH } \\
\hline Range & $7.0-8.0$ & 7.5-8.5 & $6.5-8.5$ \\
\hline Optimum & 7.0 & 7.5-8.5 & 7.0 \\
\hline \multicolumn{4}{|l|}{ Growth $\mathrm{NaCl}(\%, \mathrm{w} / \mathrm{v})$} \\
\hline Range & $0.5-4 \%$ & $0-7 \%$ & $0-7 \%$ \\
\hline Optimum & $1 \%$ & $1 \%$ & $0.5 \%$ \\
\hline Gram reaction & + & + & + \\
\hline Catalase activity & + & + & + \\
\hline Oxidase activity & - & - & - \\
\hline Urease activity & - & - & - \\
\hline reactions for nitrate & + & + & + \\
\hline \multicolumn{4}{|l|}{ Enzyme production (API ZYM) } \\
\hline Cystine arylamidase & - & - & + \\
\hline Naphthol-AS-BI-Phosphohydrolase & + & - & + \\
\hline Esterase (C4) & + & + & - \\
\hline Esterase lipase (C8) & + & + & - \\
\hline Acid phosphatase & + & + & - \\
\hline$a$-Galactosidase & + & + & - \\
\hline$\beta$-Galactosidase & + & + & - \\
\hline$a$-Glucosidase & + & + & - \\
\hline$\beta$-Glucosidase & + & + & - \\
\hline \multicolumn{4}{|l|}{ Hydrolysis of } \\
\hline Tween $20,40,60,80$ & + & + & + \\
\hline Aesculin & + & + & + \\
\hline
\end{tabular}




\begin{tabular}{|llll|}
\hline Starch & - & - & - \\
\hline Gelatin & + & + & + \\
\hline Acid production (API 50CH) & & & - \\
\hline D-Xylose & + & + & - \\
\hline L-Rhamnose & + & + & + \\
\hline Sorbitol & - & + & - \\
\hline myo-inositol & W & - & 69.2 \\
\hline DNA G + C content (mol\%) & 69.0 & $68.8-69.2$ & - \\
\hline
\end{tabular}

Strains: YIM S02566 ${ }^{\top}$; A. kwangyangense R27 ${ }^{\top}$ (data from Jung et al., 2007); A. soli $\mathrm{D}^{\top}$ (data from Chen et al., 2018).

+ positive, - negative, $w$ weakly positive

Table 2 Cellular fatty acid profile (\%) of strain YIM S02566 ${ }^{\top}$ and type strains of phylogenetically related species of the genus Aestuariimicrobium

\begin{tabular}{|llll|}
\hline Fatty acid & YIM S02566 $^{\top}$ & A. $^{\text {kwangyangense R27 }}{ }^{\top}$ & A. soli D6 $^{\top}$ \\
\hline iso-C14:0 & 7.0 & 1.5 & 2.9 \\
\hline iso-C15:0 & 0.4 & $\mathbf{1 0 . 5}$ & 15.8 \\
\hline iso-C16:0 & - & 1.6 & 1.0 \\
\hline anteiso-C15:0 & $\mathbf{6 0 . 0}$ & $\mathbf{3 7 . 9}$ & $\mathbf{4 4 . 1}$ \\
\hline Summed feature 2* & 2.9 & - & - \\
\hline Summed feature 4* & - & $\mathbf{1 6 . 0}$ & 10.8 \\
\hline
\end{tabular}

Strains: YIM S02566 ${ }^{\top}$; A. kwangyangense R27 ${ }^{\top}$ (data from Chen et al., 2018); $A$. soli D6 ${ }^{\top}$ (data from Chen et al., 2018).

*Summed feature 2 contains $\mathrm{C}_{14: 0} 3-\mathrm{OH}$ and/or iso- $\mathrm{C}_{16: 1} \mathrm{I}$

*Summed feature 4 contains iso-C17: $1 \mathrm{I}$ and/or anteiso-C17: $1 \mathrm{~B}$.

- not detected and not reported

\section{Figures}




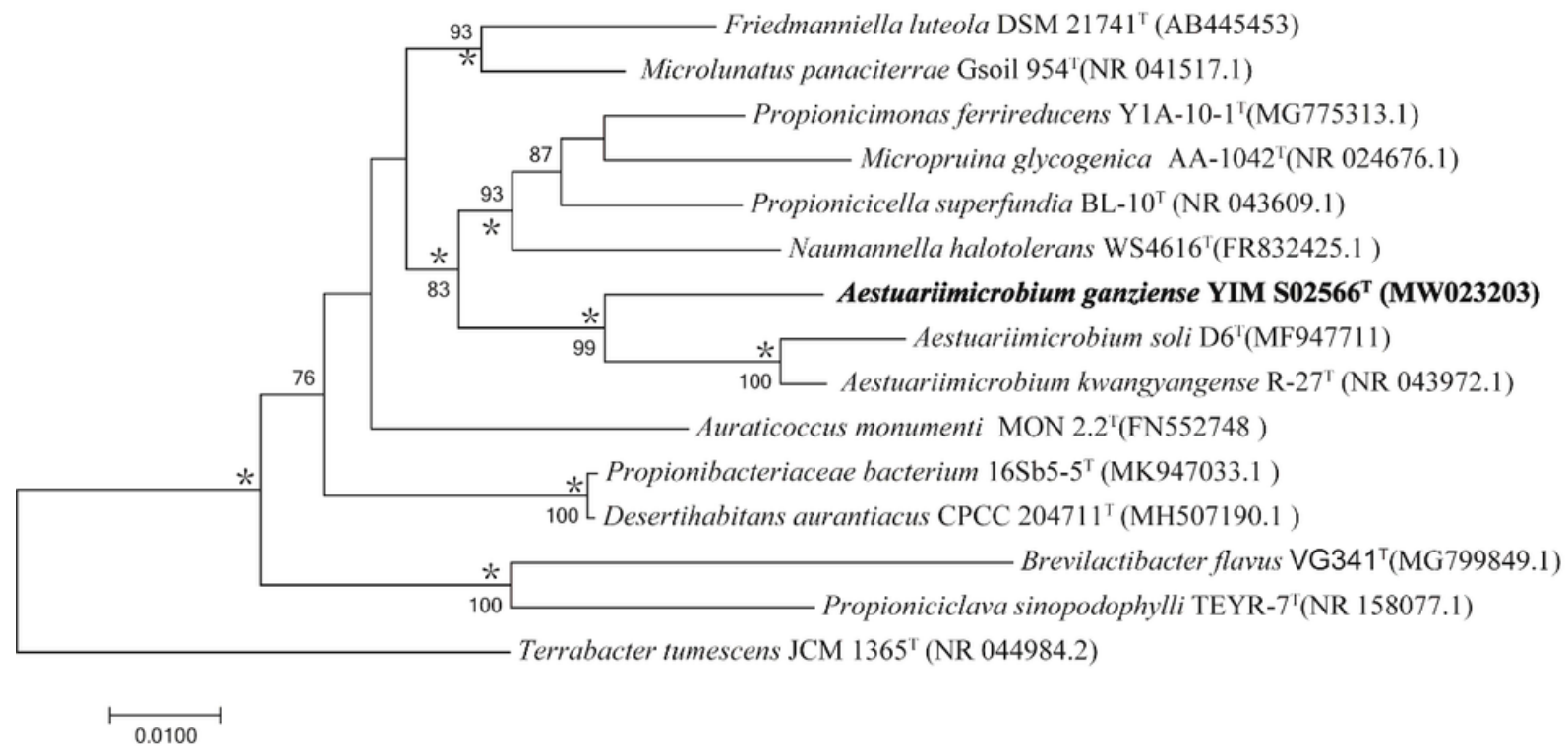

\section{Figure 1}

Neighbour-joining tree based on 16S rRNA gene sequences showing the relationships between strain YIM S02566T and some members of the family Propionibacteriaceae. Bootstrap values ( $>50 \%)$ based on 1000 replicates were shown at the branch nodes. Asterisks $\left(^{*}\right)$ indicate that the corresponding branches were also recovered in trees generated with the maximum parsimony and maximum likelihood methods. Terrabacter tumescens JCM 1365T was used as an outgroup. Bar, 1\% sequence divergence

\section{Supplementary Files}

This is a list of supplementary files associated with this preprint. Click to download.

- Supplementarymaterials.docx 